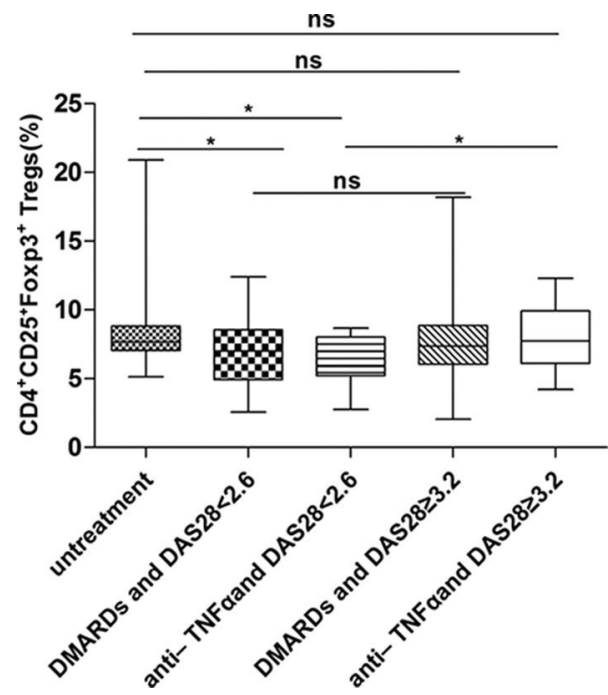

Fig4.The proportion of $\mathrm{CD} 4^{+} \mathrm{CD} 25^{+} \mathrm{Foxp}^{+}$Treg cells in treated RA patients under different treatment regimes.

Disclosure of Interests: None declared DOI: 10.1136/annrheumdis-2019-eular.2042

\section{SAT0092 LOW SERUM LEVEL OF VITAMIN D AT TIME OF DIAGNOSIS IS ASSOCIATED WITH HIGHER ONE-YEAR REMISSION RATE IN PATIENTS WITH NEWLY DIAGNOSED RA, TREATED AGGRESSIVELY DURING FOLLOW-UP: POST-HOC ANALYSES OF THE CIMESTRA TRIAL}

Mette Herly ${ }^{1}$, Kristian Stengaard-Pedersen ${ }^{2}$, Peter Vestergaard ${ }^{3}$,

Robin Christensen ${ }^{4}$, Mikkel Østergaard ${ }^{5}$, Peter Junker ${ }^{6}$, Merete L. Hetland ${ }^{7}$, Kim Hørslev-Petersen ${ }^{8}$, Torkell Ellingsen ${ }^{9} .{ }^{1}$ University of Southern Denmark, Odense University Hospital, Research Unit of Rheumatology, Department of Clinical Research, Odense, Denmark, ${ }^{2}$ Aarhus University and Aarhus University Hospital, Department of Rheumatology, Institute of Clinical Medicine, Aarhus C, Denmark; ${ }^{3}$ Aalborg University, Departments of Clinical Medicine and Endocrinology, and Steno Diabetes Center North Jutland, Aalborg, Denmark; ${ }^{4}$ Bispebjerg and Frederiksberg Hospital, Copenhagen University Hospital, Department of Musculoskeletal Statistics Unit, The Parker Institute, Frederiksberg, Denmark; ${ }^{5}$ Rigshospitalet, Glostrup, Copenhagen Center for Arthritis Research, Center for Rheumatology and Spine Diseases, Glostrup, Denmark; ${ }^{1}$ University of Southern Denmark, Odense University Hospital, Research Unit of Rheumatology, Department of Clinical Research, Odense, Denmark; ${ }^{5}$ Rigshospitalet, Glostrup, Copenhagen Center for Arthritis Research, Center for Rheumatology and Spine Diseases, Glostrup, Denmark; ${ }^{8}$ University Hospital of Southern Denmark, Danish Hospital for Rheumatic Diseases, Graasten, Denmark; ${ }^{9}$ University of Southern Denmark, Odense University Hospital, Research Unit of Rheumatology, Department of Clinical Research, Odense, Denmark

Background: Vitamin D is often low in Rheumatoid Arthritis(RA), and immunomodulatory properties of vitamin $\mathrm{D}$ might be associated with disease-course in RA.(1)

Objectives: To evaluate association between baseline vitamin $D$ metabolites and one-year remission, in newly diagnosed, treatment-naïve RA patients, aggressively treated during follow-up.

Methods: The CIMESTRA-cohort comprises 160 newly diagnosed RA patients, treated aiming at remission with methotrexate and intraarticular steroid, further randomized $1: 1$ to ciclosporine or placebo-ciclosporine.(2) A total of 158 patients had vitamin D metabolites measured at time of diagnosis. Dietary vitamin D supplementation was recommended in accordance with the national guidelines. Serum vitamin $D_{\text {total }}$ (sum of $25 \mathrm{OHD}_{2}$ and $25 \mathrm{OHD}_{3}$ ) and $1,25(\mathrm{OH})_{2} \mathrm{D}$ at time of diagnoses were measured by LC-MS/MS or RIA. $D_{\text {total }}$ were dichotomized at $50 \mathrm{nmol} / \mathrm{ll}$, and $1,25(\mathrm{OH})_{2} \mathrm{D}$ categorized in tertiles. Primary outcome was remission (DAS28-CRP $\leq 2.6)$ after one year. Associations were calculated using logistic regression, presented as Odds Ratios with 95\% Confidence Intervals $(95 \% \mathrm{Cls})$. Adjustment of analyses included sex, age, symptom duration prior to diagnosis, DAS28-CRP and season of diagnosis.

Results: In univariate analyses, neither $D_{\text {total }}$ nor $1,25(\mathrm{OH})_{2} \mathrm{D}$ at time of diagnosis predicted remission at year one. In adjusted analysis, $D_{\text {total }}<$
$50 \mathrm{nmol} / \mathrm{l}$ at time of diagnosis showed better odds for achieving one-year remission, compared to sufficient $\mathrm{D}_{\text {total }}$; OR $2.56,95 \% \mathrm{Cl}(1.11 ; 5.90) \mathrm{p}=$ 0.03 . $1,25(\mathrm{OH})_{2} \mathrm{D}$ was not associated to remission.

Conclusion: Low $D_{\text {total }}$ at time of diagnosis is associated to increased odds for achieving remission at year one in early, treatment naïve RA patients, treated aggressively during follow-up.

\section{REFERENCES}

[1] Jeffery LE, et al. Vitamin D in rheumatoid arthritis-towards clinical application. NatRevRheumatol. 2015.

[2] Hetland $\mathrm{ML}$, et al. Combination treatment with methotrexate, cyclosporine, and intraarticular betamethasone compared with methotrexate and intraarticular betamethasone in early active rheumatoid arthritis: an investigatorinitiated, multicenter, randomized, double-blind, parallel-group, placebocontrolled study. Arthritis Rheum. 2006;54:1401-9.

Acknowledgement: Sören Möller, biostatistician at OPEN, Odense, for statistical support

Disclosure of Interests: Mette Herly Grant/research support from: Pfizer Denmark, unrestricted grant, used for salary.

The Danish Rheumatism Association, patient association, 6 months salary as part of PHD study, Speakers bureau: The Danish Rheumatism Association, patient association, speakers Fee 500 Euro, Kristian Stengaard-Pedersen: None declared, Peter Vestergaard Speakers bureau: Amgen, Eli Lilly, Novartis, MSD, Servier, Robin Christensen Grant/research support from: AbbVie Inc, and the Oak Foundation, Speakers bureau: Roche, Mikkel stergaard Grant/research support from: Abbvie, Celgene, Centocor Merck, Novartis, Consultant for: Abbvie, BMS, Boehringer-Ingelheim, Celgene, Eli Lilly, Hospira, Janssen, Merck, Novartis, Novo, Orion, Pfizer, Regeneron, Roche, and UCB, Speakers bureau: Abbvie, BMS, Boehringer-Ingelheim, Celgene, Eli Lilly, Hospira, Janssen, Merck, Novartis, Novo, Orion, Pfizer, Regeneron, Roche, and UCB, Peter Junker: None declared, Merete L. Hetland Grant/research support from: BMS, MSD, AbbVie, Roche, Novartis, Biogen, Pfizer, Consultant for: Eli Lilly, Speakers bureau: Orion Pharma, Biogen, Pfizer, CellTrion, Merck, Samsung Bioepis, Kim Hørslev-Petersen Grant/research support from: AbbVie during the conduct of the study, Torkell Ellingsen: None declared DOI: 10.1136/annrheumdis-2019-eular.1569

\section{SAT0093 THE ASSESSMENT OF THE SYNOVIAL VASCULARIZATIONWITH POWER DOPPLER ULTRASONOGRAPHY AND ITS CORRELATION WITH THE SYSTEMIC INDICATORS OF INFLAMMATION AND WITH THE DISEASE ACTIVITY}

Michał Jakubaszek ${ }^{1}$, Maria Maślińska ${ }^{1}$, Mateusz Płaza ${ }^{2}$, Małgorzata Mańczak ${ }^{3}$, Brygida Kwiatkowska' ${ }^{1}$ National Institute of Geriatrics, Rheumatology and Rehabilitation, Early Arthritis Clinic, Warsaw, Poland; ${ }^{2}$ National Institute of Geriatrics, Rheumatology and Rehabilitation, Radiology Depa rtment, Warsaw, Poland; ${ }^{3}$ National Institute of Geriatrics, Rheumatology and Rehabilitation, Department of Gerontology and Public Health, Warsaw, Poland

Background: Rheumatoid arthritis (RA) is an autoimmune disease with the predominant synovial inflammation. The disease activity and inflammatory markers in the serum indicate an active stage of the disease with a risk of joint destruction. As the synovial hypervascularity is considered a proof of an active inflammation, its assessment with different scoring methods in Power Doppler ultrasonography (PDUS) is being discussed. Objectives: We investigated correlation of synovial vascularization (assessed in PDUS) with inflammatory markers and disease activity. We compared two methods for the evaluation of synovial vascularization : quantative and semi-quantitative.

Methods: We studied 50 RA patients, mean age of 58 years, predominantly female (F/M ratio $3: 1$ ), mean disease duration span of 9,5 years. Data on: age, sex, patient global assessment of pain measured by a $100-\mathrm{mm}$ visual analog scale (VAS) were obtained. The disease activity state was defined by DAS28 score (score in 28 joints) and simplified disease activity index (SDAI). Of the laboratory tests: erythrocyte sedimentation rate $(E S R)$, serum C-reactive protein level $(C R P)$, the presence of rheumatoid factor(RF) and anti-cyclic citrullinated peptide antibodies (ACPA) were performed. In ultrasound, the examination of the synovial vascularity, as a symptom of inflammation, was scored in PDUS, utilizing the validated scoring system, grade 0 - lack of flow, 1 - one to two vessels visible within the synovium, 2 - numerous vessels occupying up to $50 \%$ of the thickened synovium, 3 - numerous vessels occupying over $50 \%$ of the synovium volume. The second quantitatively scale was also used, with the color fraction index $(\mathrm{CFI})$, defined as the ratio of the 